\title{
Women and Infertility in a Pronatalist Culture: Mental Health in the Slums of Mumbai
}

This article was published in the following Dove Press journal:

International Journal of Women's Health

Lisa Roberts (D)

Solomon Renati $\mathbb{D i D}^{2}$

Shreeletha Solomon (D) $^{3}$

Susanne Montgomery ${ }^{4}$

'School of Nursing, Loma Linda University, Loma Linda, CA 92350, USA;

${ }^{2}$ Department of Psychology, Veer Wajekar A. S. \& C. College, Navi Mumbai 400702, India; ${ }^{3}$ Veer Wajekar

A. S. \& C. College, Navi Mumbai 400702, India; ${ }^{4}$ School of Behavioral Health, Behavioral Health Institute, Loma Linda University, Loma Linda, CA 92350, USA
Correspondence: Lisa Roberts School of Nursing, Loma Linda University, I 1262 Campus Street, Loma Linda, CA 92350, USA

$\mathrm{Tel}+\mathrm{I}(909) 558-1000$

Fax +l (909) 558-07I9

Email Iroberts@llu.edu
Background: Infertility is a global problem, with high prevalence in India. As a pronatalist society, infertility is particularly problematic in India, causing stigma, shame, and blame especially for women. Infertility consequences for women include discrimination, social exclusion, and abandonment, putting them at high risk for mental health distress. Furthermore, mental health is highly stigmatized and specialized care is largely unavailable. Despite the cultural importance of childbearing, research on infertility distress and resulting mental health sequelae is lacking, particularly among low-income women. The purpose of this study is to assess mental health, using validated scales, among Mumbai slum-dwelling women with a history of infertility.

Methods: We conducted a mixed-method, cross-sectional study. A focus group discussion with community health workers $(n=7)$ informed the development of a comprehensive survey. The survey consisted of validated scales whenever possible, in addition to questions pertaining to women's sociodemographic and reproductive history. After rigorous forward and back translation, the surveys were conducted as face-to-face structured interviews due to low literacy levels and the research naiveté of our respondents. Interviews were conducted by culturally, linguistically, gender-matched, trained research assistants.

Results: Mumbai slum-dwelling women of reproductive age suffering from infertility $(\mathrm{N}=$ 74) participated. Most (85\%) women and their husbands (66\%) reported previous infertility testing. Participants had elevated mental health distress (anxiety and depression symptomology) largely explained by general health, length of marriage, and coping strategy employed. Conclusion: Women facing the double stigma of mental health and infertility need innovative programs to address their challenges.

Keywords: infertility, mental health, stigma, low-income women, Mumbai, India

\section{Introduction}

Infertility, defined by the World Health Organization (WHO) as failure to conceive after at least 12 months of unprotected sexual intercourse, ${ }^{1}$ is a global public health problem with high prevalence in South Asia. ${ }^{2}$ In India, the estimated prevalence of overall infertility (primary and secondary) is roughly $2.5-14 \%{ }^{3}$ Common causes of female infertility include ovarian, uterine, tubal and peritoneal disorders, as well as nutritional deficiencies, anemia, thyroid dysfunction, genetic disorders, and mental health problems such as anxiety and depression. Common causes of male infertility include poor sperm quality, structural or hormonal disorders, genetic disorders, decreased libido due to substance abuse or depression, or impotence, which is often linked to alcohol, or certain prescriptions such as antihypertensive or antiseizure medications. ${ }^{4}$ Globally, primary infertility (defined as the inability to attain 
a live birth) accounts for $2 \%$ of infertile women, whereas secondary infertility (women who had at least one live birth previously) accounted for approximately $10.5 \%{ }^{2}$ In India, primary infertility prevalence is estimated to range from $3.9 \%$ to $16.8 \%{ }^{5}$ Government funding, public health sector availability, and insurance coverage for infertility testing and treatment are almost non-existent in lowmiddle-income countries (LMICs), ${ }^{6}$ creating unequal access to such services and contributing to health disparities. Those who can afford to do so, most often pay cash.

Despite the fact that infertility affects both men and women fairly equally, ${ }^{7-9}$ in many societies, the woman is most often blamed when she does not get pregnant, resulting in mental health distress, stigma, discrimination, social exclusion, and abandonment. ${ }^{2,10-12}$ Infertility is associated with lower quality of life, marital discord, ${ }^{13}$ with greater psychosocial consequences for women. ${ }^{3,14}$ Additionally, infertile women with poor social support, high sociocultural pressure to have children (especially sons), maladaptive coping (ie, emotion focused/avoidance), prior trauma or mental health disorders, and overinvolved family members, are at particularly high risk for distress, including depression, and anxiety. ${ }^{5,13-17}$ Typically, couples in India are expected to conceive within the first year of marriage and face considerable social pressure and coercion when that does not happen, ${ }^{15,18-20}$ resulting in increased distress related to infertility. ${ }^{15}$

Consistent with Life Course Theory, conception, pregnancy, and childbirth are major components in women's anticipated life trajectory. 5,13,21 Infertility represents a major turning point marked by the agony of unfulfilled fertility ambitions, and challenges to one's self-worth and confidence. $^{5,13,15,21,22}$ Furthermore, in traditional patriarchal societies such as many found in India, a woman's status and value is inextricably linked to her fertility. 5,10,12 Although allopathic infertility treatment and reproductive technology is readily available in India, it is not equally available to all due to the expense and time-intensive nature of treatment. ${ }^{3,12,23}$ Sarkar and Gupta ${ }^{3}$ found that while roughly $80 \%$ of infertile women in India sought treatment, $33 \%$ of these treatments were classified as traditional treatments or religious rituals. In the Indian social context, women who cannot seek treatment or find treatment ineffective, may be at particularly high risk for mental health consequences.

With the importance placed on childbearing (characterized as mandatory) in this pronatalist culture, women's failure to produce offspring creates loss of status on top and stigma, putting affected women at high risk for mental health problems. ${ }^{5}$ Studies in other pronatalist cultures have indicated that women without children are perceived more negatively than those who have children, and among infertile women, perceived community pressure to have children is associated with distress. ${ }^{24,25}$ Yet research on culturally specific infertility distress and the mental health sequelae of infertility in India is lacking, ${ }^{3,12,23,26}$ particularly among low-income women. Therefore, the purpose of this study is to assess mental health among a sample of Mumbai slum-dwelling women with a history of infertility.

\section{Methods}

We conducted a mixed-method, cross-sectional study in Mumbai slums. First, we used purposive sampling to recruit seven Accredited Social Health Activist (ASHA) workers (similar to community health workers) from different local slum areas who are familiar and serving in these areas to support the local community on health issues. We then conducted a qualitative formative focus group discussion $(n=7)$ with them to explore, using their expert perspective, the prevalence of infertility within their communities and how women are affected. The focus group was audio-recorded, transcribed, coded and analyzed for salient themes. ${ }^{27}$ Based on these results we developed a comprehensive survey aligned with the identified themes, using validated scales whenever possible. Questions pertained to women's reproductive problems and related psychosocial issues. Our collaborating ASHA workers, who live and work in their communities are typically assigned to an area serving a population of 1000 residents and are responsible for creating health awareness in the community-especially pertaining to reproductive health, hygiene, and immunizations. They are also responsible for keeping vital statistics for the women and children. ${ }^{28}$ With their input and collaboration, we were then able to recruit women with known infertility burdens (a very hard to reach group due to the associated stigma) using purposive and snowball sampling techniques.

Institutional Review Board (IRB) approval, in accordance with the declaration of Helsinki, was received from Loma Linda University in the US and Ethics committee approval from Veer Wajekar A. S. and C. College in India, prior to data collection. We translated the IRB-approved English version of the survey instrument into Hindi and Marathi, the local languages spoken by our target population. Bilingual scholars outside of the research team completed 
the translations utilizing the independent forward and backward translation technique to ensure cultural and functional equivalence, rather than simply literal translation. ${ }^{29}$ Surveys were then shared with ASHA workers for further feedback.

ASHA workers supported by culturally, linguistically, gender-matched, trained research assistants recruited participants. After verbally reviewing the study information and consent for and obtaining written informed consent (signed or marked with thumbprint), the surveys were conducted as face-to-face structured interviews due to low literacy levels and research naiveté of our target population. The research assistants read the questions and response options verbatim to participants and recorded the responses indicated. Among women who expressed an interest in a future intervention for wellbeing, we also collected contact information, which we kept separately from their de-identified survey data. Data were collected in February and March 2020. Quantitative data were analyzed using IBM SPSS Statistics program, version 26.

\section{Measures}

\section{Descriptive Variables}

Demographic variables included age, marital status, religion, education, occupation, and socioeconomic status. Additional descriptive variables included general health status and reproductive health history, as well as details pertaining to infertility testing for the participant and her partner, as well as open-ended questions about any treatments tried and their beliefs pertaining to the cause or reason for their infertility.

\section{Validated Scales}

The Hopkins Symptoms Check List-I0 (HSCL-10)

Has been used successfully in a number of low income and low education international populations, including in Pakistan (Urdu translation), ${ }^{30}$ and in Chhattisgarh, India (Hindi translation) $^{31}$ with Cronbach's $\alpha$ of 0.76 to 0.86 . It was therefore, chosen for use among this population who share cultural similarities and language. The measure consists of 10 items, which are rated on a Likert-type scale ranging from (1) not at all to (4) extremely, with higher scores representing more symptoms of anxiety and depression. Like Syed et $\mathrm{al}^{30}$ we used a mean of 1.65 or greater as a cut-off score indicating presence of notable mental health symptoms (anxiety and depression). With the current sample, reliability of HSCL-10 is demonstrated (Cronbach's $\alpha=0.89$ ).

\section{The I2-Item Version of the Social Provision Scale} (SPS)

Assesses the perception of social support received from others. ${ }^{32}$ A 4-point Likert-type scale of (1) strongly disagree to (4) strongly agree is summed for a possible score ranging from 12 to 48 , with higher scores indicating greater social support perceived. This scale was previously used among poor women in rural Chhattisgarh, India and found to be reliable as indicated by Cronbach's $\alpha$ of 0.69 to $0.74{ }^{33,34}$ In the current study Cronbach's $\alpha=0.75$.

\section{The Short Form of the Brief RCOPE}

Is a 7-item scale measuring positive and negative religious coping (three questions each) with response options (0) not at all, to (3) a great deal, and a final question measuring to what extent religion is used to cope with stressful situations. The Likert-type response options for the last item are (0) not involved at all, to (3) very involved. ${ }^{35,36}$ This scale too was previously found to be adequately reliable (Cronbach's $\alpha$ 0.70) in a sample of poor Indian women ${ }^{33}$ and in this sample was 0.90 for the positive subscale.

\section{The Shortened Ways of Coping-Revised (SWC-R)}

Is a 14-item Likert-type scale containing two sub-scales, wishful thinking (emotion focused or avoidance) and practical coping, two distinct coping strategies. ${ }^{37}$ Each subscale is summed separately, with higher scores indicating more frequent use of the particular coping strategy. ${ }^{38}$ Response options are (0) never used, to (3) regularly used. Previously used in India, the SWC-R was found to be reliable (Cronbach's $\alpha 0.88)^{34}$ and in the current study is 0.75 .

\section{The Infertility Stigma Scale (ISS)}

Has 27 items total, with four subscales: self-devaluation (7 items), social withdrawal (5 items), public stigma (9 items), and family stigma (6 items). Likert-type response items (1) totally disagree, to (5) totally agree, and higher scores indicate more stigma. Originally developed and validated for Chinese women (Cronbach's $\alpha$ 0.94), ${ }^{39}$ a population with similar traditional patriarchal norms and son preference, it has since been used with Persian ${ }^{40}$ and Turkish ${ }^{41}$ samples, with good reliability. In the current study the Cronbach's $\alpha$ is 0.94 .

\section{The Satisfaction with Life Scale (SWLS)}

Is a 5-item scale with response options (1) strongly disagree to (7) strongly agree. Summed items create a possible score of five to 35 , with higher scores indicating 
greater satisfaction with life. ${ }^{42,43}$ The SWLS is easily understood and applicable in diverse populations and settings, and has previously been used in India (Cronbach's $\alpha$ 0.68 to 0.81$).{ }^{31,43}$ In the current study, Cronbach's $\alpha=0.84$.

\section{Additional Scales Autonomy}

An author developed autonomy scale used in previous studies in India, ${ }^{34}$ contains questions specific to women in Indian society who often have low autonomy. This fouritem scale is summed, so that higher scores indicate greater autonomy. Cronbach's $\alpha=0.68$.

\section{Social Norms}

A 10-item author developed scale measuring social norms pertaining to infertility employed Likert-type response option (1) strongly disagree, to (5) strongly agree. Items were summed after three items were reversed, for a possible score of $10-50$, with higher scores indicating greater endorsement of social norms. Cronbach's $\alpha=0.63$ indicated adequate reliability.

\section{Results}

\section{Participants}

The study sample $(\mathrm{N}=74)$ consisted of women 19 to 42 years old, residing in established slums of Mumbai. More than half (58.1\%) lived in a nuclear family context rather than a joint family (41.9\%), and identified themselves as daughter-in-law or wife (98.6\%). The average age was 27 $(M=26.69, S D 5.38)$ and women had on average been married for a little under eight years $(M=7.66, S D$ 5.57). Most were Hindu (63.5\%) women, and worked as unskilled workers or homemakers (73.0\%). Their education levels were fairly evenly spread across the continuum with roughly a quarter of the participants indicating having no education/being illiterate, or having primary, secondary (up to 10th grade), or highersecondary (12th grade) education. In general, participating women deemed themselves as physically healthy (62.2\%), indicating no problems. However, nearly half of the women self-identified as experiencing psychosocial problems ( $45.1 \%$ anxiety, $4.2 \%$ depression). The majority (85.1\%) had undergone some type of infertility testing, and many of their husbands had done the same (66.2\%). Only 12 women (16.2\%) had ever been pregnant, and the average number of pregnancies among them was 1.17 (SD 0.39).
In this group of women with fertility challenges, women who expressed an interest in a future intervention $(\mathrm{n}=24)$ vs those who did not $(\mathrm{n}=50)$, we found no significant demographic, reproductive history, or infertility testing differences. However, the women's self-assessment of health status and psychosocial health were different in that they were statistically more likely to identify general health problems $X^{2}(2)=13.88, p=0.001$, and psychosocial problems $X^{2}(2)=7.98, p=0.014$ (see Table 1 for further details).

\section{Variables of Interest}

The average participant HSCL score was above the 1.65 cut-off score indicating anxiety and depressive symptomology $(M=1.98, S D$ 0.38). When comparing the subgroup of women desiring an intervention with the rest of the participants using independent samples $t$-test, these women were significantly more likely to endorse social norms pertaining to infertility $t(70)=-2.62, p=0.011$, $95 \%$ CI $[-7.88,-1.07]$, and had higher levels of autonomy $t(72)=-2.29, p=0.025,95 \%$ CI $[-2.11,-0.15]$. While there was no significant difference in the total score of the Infertility Stigma Scale, one of the subscales, Family Stigma, did show a significant difference $t(71)=-2.34$, $p=0.022,95 \%$ CI $[-6.04,-0.47]$, with women wanting an intervention scoring higher. HSCL scores were also significantly higher, indicating worse mental health symptomology for this sub-group than the rest of the participants $t(71)=-3.45, p=0.001,95 \%$ CI $[-1.01,-0.27]$.

Additionally, we also noted that negative religious coping was higher and satisfaction with life lower in this subgroup. Though not statistically significant, likely given the small sample size for our subgroup analyses, these associations were trending/approaching significance at $p<0.10$. See Table 2 for details.

\section{Response to Open-Ended Questions}

Fifty-nine of our 74 participants responded to an openended question about treatments or remedies they had tried to improve their chances of conception. Responses revealed that $40(54 \%)$ participants had tried some sort of treatment; one indicated having had surgery, one noted thyroid treatment, another noted sonogram and medication, and the remainder indicated non-specific medication only. Nineteen participants indicated they had not tried any treatments or remedies.

In another open-ended question, participants were asked what they thought caused their challenges in having 
Table I Demographics and Health of Participants $(\mathrm{N}=74)$

\begin{tabular}{|c|c|c|c|}
\hline \multicolumn{2}{|l|}{ Characteristics } & \multirow{2}{*}{$\begin{array}{l}\text { Participants without Desire for } \\
\text { Intervention }(n=50) \\
\text { n (\%) }\end{array}$} & \multirow{2}{*}{$\begin{array}{l}\text { Participants Desiring } \\
\text { Future Intervention } \\
(n=24)\end{array}$} \\
\hline & & & \\
\hline \multirow[t]{3}{*}{ Household position $(n=74)$} & Wife & $30(60.0)$ & $13(54.2)$ \\
\hline & Daughter-n-law & $19(38.0)$ & II (45.8) \\
\hline & Daughter & I (2.0) & 0 \\
\hline \multirow[t]{2}{*}{ Family style $(n=74)$} & Nuclear & $20(40.0)$ & II (45.8) \\
\hline & Joint & $30(60.0)$ & $13(54.2)$ \\
\hline \multirow[t]{4}{*}{ Religion $(n=74)$} & Hindu & $33(66.0)$ & $14(58.3)$ \\
\hline & Muslim & $12(24.0))$ & $6(25.0)$ \\
\hline & Buddhist & $3(6.0)$ & $3(12.5)$ \\
\hline & Other & $2(4.0)$ & $\mathrm{I}(4.2)$ \\
\hline \multirow[t]{4}{*}{ Highest level of education $(n=74)$} & None (illiterate) & $13(26.0)$ & $5(20.8)$ \\
\hline & Primary & $16(32.0)$ & $5(20.8)$ \\
\hline & Secondary & II (22.0) & $7(29.2)$ \\
\hline & $\begin{array}{l}\text { Higher-secondary } \\
\text { or graduate }\end{array}$ & $10(20.0)$ & $7(29.2)$ \\
\hline \multirow[t]{2}{*}{ Current occupation $(n=74)$} & $\begin{array}{l}\text { Unskilled worker/ } \\
\text { Homemaker }\end{array}$ & $39(78.0)$ & $15(62.5)$ \\
\hline & $\begin{array}{l}\text { Semi-skilled worker to } \\
\text { semi-professional }\end{array}$ & II (22.0) & $9(37.5)$ \\
\hline \multirow[t]{3}{*}{ Monthly family income $(n=70)$} & $\leq$ Rs. $209 \mid-10,356$ & $15(31.9)$ & $9(39.1)$ \\
\hline & Rs. $10,357-20,7 \mid 4$ & $25(53.2)$ & $12(52.2)$ \\
\hline & Rs. $20,7 \mid 5-41,430+$ & $7(14.9)$ & $2(8.7)$ \\
\hline \multirow[t]{3}{*}{ Health problems $(n=74)^{* *}$} & None & $38(76.0)$ & $8(33.3)$ \\
\hline & Anemia & $5(10.0)$ & $10(41.7)$ \\
\hline & Other $^{a}$ & $7(14.0)$ & $6(25.0)$ \\
\hline \multirow[t]{3}{*}{ Psychosocial problems $(n=7 \mathrm{I})^{*}$} & None & $31(66.0)$ & $8(33.3)$ \\
\hline & Anxiety & $16(34.0)$ & $15(62.5)$ \\
\hline & Depression & 0 & I (4.2) \\
\hline \multirow[t]{2}{*}{ Had infertility testing $(n=74)$} & No & $9(18.0)$ & $2(8.3)$ \\
\hline & Yes & $4 \mathrm{I}(82.0)$ & $22(91.7)$ \\
\hline \multirow[t]{3}{*}{ Husband had infertility testing $(n=74)$} & No & $15(30.0)$ & $10(41.7)$ \\
\hline & Yes & $35(70.0)$ & $14(58.3)$ \\
\hline & & $M(\mathrm{SD})$ & $M(S D)$ \\
\hline Age $(n=74)$ & & $26.72(5.34)$ & $26.63(5.59)$ \\
\hline Years married $(n=74)$ & & $7.92(5.98)$ & $7.13(4.68)$ \\
\hline Mother's age at first pregnancy $(n=12)$ & & $23.17(1.47)$ & $22.50(9.20)$ \\
\hline $\begin{array}{l}\text { If ever pregnant, number of pregnancies }(n= \\
\text { 12) }\end{array}$ & & $\mathrm{I} .17(0.4 \mathrm{I})$ & $1.17(0.41)$ \\
\hline
\end{tabular}

Notes: ${ }^{*} p<0.05,{ }^{*} p<<0.01$ per $X^{2}$ or $t$-test. Other ${ }^{a}=$ Thyroid disease, weakness, hypotension, Tuberculosis, kidney stones, headache, asthma, irregular menses, hysterectomy.

a baby and $56(76 \%)$ responded with short answers. Nine respondents specifically indicated their husbands had infertility or related issues such as alcoholism; eight indicated female causes of infertility such as irregular menses, and ovarian, tubal, or uterine problems; four specifically cited stress as the cause; three reported other 
Table 2 Mean Scores on Variables of Interest and Independent Samples $t$-Test Comparisons

\begin{tabular}{|c|c|c|c|c|}
\hline \multirow[t]{2}{*}{ Scale } & \multirow[t]{2}{*}{$\begin{array}{l}\text { Possible } \\
\text { Range }\end{array}$} & \multirow[t]{2}{*}{$\begin{array}{l}\text { Mid- } \\
\text { Range } \\
\text { Score }\end{array}$} & $\begin{array}{l}\text { Participants without Desire for } \\
\text { Intervention }(n=50)\end{array}$ & $\begin{array}{l}\text { Participants Desiring } \\
\text { Future Intervention } \\
(n=24)\end{array}$ \\
\hline & & & $M(S D)$ & $M(S D)$ \\
\hline Social Norms $(n=72)^{*}$ & $10-50$ & 30 & $24.52(7.34)$ & $29.00(5.64)$ \\
\hline Social Support $(n=73)$ & $12-48$ & 30 & $39.10(5.55)$ & $38.54(7.19)$ \\
\hline Positive RCOPE $(n=74)$ & $0-9$ & 4.5 & $1.56(2.75)$ & $1.79(2.75)$ \\
\hline Negative RCOPE $(n=73)^{+}$ & $0-9$ & 4.5 & $5.44(2.10)$ & $5.61(1.97)$ \\
\hline Overall religiosity $(n=74)$ & $0-3$ & 1.5 & $2.36(0.85)$ & $2.45(0.88)$ \\
\hline Wishful thinking $(n=74)$ & $0-21$ & 10.5 & $12.70(4.70)$ & I3.37 (3.24) \\
\hline Practical coping $(n=73)$ & $0-21$ & 10.5 & $14.67(4.64)$ & I5.33 (4.07) \\
\hline Autonomy $(n=74)$ & $1-12$ & 6.5 & $7.08(1.94)$ & $8.20(2.06)$ \\
\hline Infertility Stigma Total $(n=73)$ & $27-135$ & 81 & $64.67(26.78)$ & $75.12(21.28)$ \\
\hline Self-devaluation subscale $(n=74)$ & $7-35$ & 21 & $18.56(9.44)$ & $20.25(7.50)$ \\
\hline Social Withdrawal subscale $(n=74)$ & $5-25$ & 15 & $14.76(5.85)$ & $15.62(4.37)$ \\
\hline Public Stigma subscale $(n=74)$ & $9-45$ & 27 & $21.82(11.13)$ & $25.67(10.32)$ \\
\hline Family Stigma subscale $(\mathrm{n}=73)^{*}$ & $6-30$ & 18 & $10.33(5.40)$ & I3.58 (5.99) \\
\hline Mental health: HSCL $(n=73)^{* *}$ & $\begin{array}{l}\mathrm{I}-4 \\
\text { (cut off I.65) }\end{array}$ & 1.5 & $1.78(0.7 I)$ & $2.43(0.79)$ \\
\hline Life satisfaction $(n=74)^{+}$ & $5-35$ & 20 & $22.70(7.43)$ & $19.20(8.89)$ \\
\hline
\end{tabular}

Notes: ${ }^{+} p<0.10,{ }^{*} p<0.05, * * p<0.01$.

health problems such as thyroid and hypertension; indeed, most $(\mathrm{n}=32 ; 57 \%)$ indicated that they had no idea what had caused their infertility.

\section{Bivariate Analysis of Mental Health}

We explored the relationship of a set of independent variables associated with mental health (HSCL scores), through bivariate analysis for the entire sample $(\mathrm{N}=74)$. Significantly associated variables included older age $(0.358, p=0.002)$, higher skilled occupation $(0.300, p=0.010)$, married longer $(0.329, p=0.004)$, more general health issues identified $(0.476, p=0.000)$, more self-identified psychosocial problems $(0.370, p=0.002)$, more wishful thinking and practical coping $(0.443, p=0.000$ and $0.328, p=0.005$, respectively), greater endorsement of social norms $(0.414, p=0.000)$, better life satisfaction $(0.371, p=0.001)$, higher total infertility stigma (0.523, $p=0.000)$, and all of the infertility subscales were also higher; self-devaluation $(0.500, p=0.000)$, social withdrawal $(0.399, p=0.000)$, public stigma $(0.473, p=$ $0.000)$, as well as family stigma $(0.371, p=0.001)$.

For those interested in a future intervention $(\mathrm{n}=24)$, bivariate analysis of HSCL with demographics and independent variables was significant for greater number of years married $(0.489, p=0.018)$, higher infertility stigma total score $(0.422, p=0.045)$, and higher infertility public stigma subscale $(0.426, p=0.042)$.

\section{Analysis of Predictors of Mental Health Change}

For our multivariate analysis we entered only variables that were bivariate significantly associated with HSCL (age, occupation, years married, general health, psychosocial problems, wishful and practical coping, social norms, life satisfaction, and total infertility stigma). As noted in Table 3, while only years married (longer) general health (poorer) and having a more wishful thinking coping style remained significant, the model explained $65 \%$ of the variance.

\section{Discussion}

The average age of our participants was just under 27 years of age. On average they had been married approximately 7.5 years, indicating that most were married at about 19 years of age. Therefore, it is not surprising that the "usual reasons" of older age and older age at marriage did not apply to our group of women grappling with infertility and related distress. ${ }^{3,14}$ However, a previous study among low to middle-income Indian women indicated that greater infertility distress was associated with being married more than five years, ${ }^{26}$ which aligns with our findings that being married for a longer time, was significantly associated with mental health (HSCL scores) 
Table 3 Summary of Regression Analysis for Variables Predicting Mental Health $(\mathrm{N}=74)$

\begin{tabular}{|l|l|l|l|}
\hline Variables & B & SE B & $\boldsymbol{\beta}$ \\
\hline Constant & 0.47 & 0.64 & \\
Age & -0.17 & 0.02 & -.11 \\
Occupation & 0.23 & 0.18 & 0.12 \\
Health & 0.38 & 0.12 & $0.34^{* *}$ \\
Psychosocial problems & 0.02 & 0.18 & 0.01 \\
Years married & 0.06 & 0.02 & $0.35^{*}$ \\
Social norms & 0.01 & 0.01 & 0.03 \\
Coping style - Wishful thinking & 0.07 & 0.02 & $0.32^{*}$ \\
Coping style - Practical & -0.01 & 0.02 & -.01 \\
Self-devaluation & 0.02 & 0.01 & 0.21 \\
Social withdrawal & 0.01 & 0.02 & 0.06 \\
Public stigma & -0.01 & 0.02 & -.03 \\
Family stigma & -0.01 & 0.02 & -.01 \\
Life satisfaction & -0.01 & 0.01 & -.14 \\
\hline$R^{2}$ & 0.65 & \\
\hline F for change in $R^{2}$ & $7.4 I^{* * *}$ \\
\hline
\end{tabular}

Notes: $* p<0.05, * * p<0.01, * * * p<0.001$.

for the total sample as well as for the women in the subgroup. Our data concur with others that women married longer than five years without a child had higher infertility distress, likely due to progressive social pressure and diminishing hopes of having a child the longer infertility goes on. ${ }^{13,26}$

The majority (85\%) of the women in our sample reported having had infertility testing, which is consistent with previous studies in India $^{3}$ regardless of income. Given that the average length married was over seven and a half years and women are expected to become pregnant within the first year of marriage, it is likely that most were suffering infertility for over five years. Having a baby is critical to families and funds will be found to explore how fertility challenges can be remedied. It is also not surprising that while males are equal contributors to infertility, ${ }^{7-9}$ fewer husbands $(66 \%)$ had been tested. In many societies, including in India, there is a general blaming of women for infertility. $3,9,14,15,17$ Interestingly, among participants who indicated known causes of their infertility situation, male and female-specific causes were indicated almost equally, reflecting the general literature on prevalence of male and female causes. ${ }^{7-9}$ Our findings that most participants, despite their low income sought treatments (54\%), aligns with previous studies indicated that 30-50\% of Indian women choose allopathic treatment for infertility, with the remainder choosing traditional remedies or religious rituals. Allopathic treatment is typically beyond the means of low- and middle-income women ${ }^{3,23}$ but having infertility challenges is critical and thus likely results in higher rates of seeking medical guidance than would usually be expected in a similar group of low incomewomen.

General health was a significant predictor of mental health. The health problems noted in the total sample included thyroid disease, weakness, hypotension, tuberculosis, kidney stones, headache, asthma, irregular menses, and hysterectomy. Only 12 of our 74 participants had ever been pregnant, likely representing primary infertility at a much higher percentage than found in the literature. ${ }^{2}$ Indeed, many of our participant's health complaints aligned with known risks for infertility. ${ }^{4}$ Of note, Patel et $\mathrm{al}^{26}$ found that uterine abnormalities and gynecological surgery greatly increased distress. Hence, it is not surprising that general health problems were a significant predictor or greater mental health symptomology (anxiety and depression) in our sample.

Similar to findings in the literature, ${ }^{26}$ higher wishful thinking, a maladaptive emotion-focused and avoidant coping strategy, was also significantly associated with HSCL scores and remained significant in the regression analysis for our total sample. Healthy coping strategies on the other hand, have been shown to help women weather the difficulties of infertility with better mental health outcomes. $^{26,44,45}$

Unlike previous studies that have found that higher education was a protective factor for infertility and related mental health distress, ${ }^{3,14}$ educational level was not significant in the current study. This may be due to the fairly even low educational levels of our slum-dwelling participants, ranging mostly $(>70 \%)$ from illiteracy, to highersecondary.

Of note, our sample did not report high rates of domestic violence. This was contrary to anticipated results, and previous studies indicate an increased rate of emotional, physical, and sexual violence reported by infertile women. $^{12,15,16,46}$ However, in traditional Indian culture, a certain level of domestic violence towards women is accepted as the norm, ${ }^{12}$ and it may be that infertilityrelated domestic violence was taken in stride on that account. On the other hand, while care was taken to conduct the structured interviews with adequate privacy, the women may have feared being overheard. Slums are tightknit communities which are often a source of social support enhancing resilience, ${ }^{47,48}$ however, in the context of 
infertility, this may be a disadvantage. Risk of domestic violence is already very high in the slums. ${ }^{49}$ Spousal support was found to be an important predictor of infertility distress among upper-class Indian women, ${ }^{15,26}$ it is possible that the same is true for low-middle income women. Furthermore, Patel et $\mathrm{al}^{15}$ found that seeking infertility was best kept secret to avoid intrusive questions, violation of privacy, and overinvolvement of family members who often had unrealistic expectations for treatment outcomes. Unfavorable outcomes (ie, continued infertility) carry with it many risks to women from blame and escalating violence to divorce or abandonment. ${ }^{15-17}$

For many women, the need for privacy must therefore be carefully weighed against the need for social support, which may explain why social support was not significantly associated with mental health in our sample. This finding ran contrary to our a priori assumptions and previous literature that identifies an inverse relationship between perceived social support and mental health problems. ${ }^{14}$ Total infertility stigma, as well as public stigma and family stigma subscales, were significantly associated with increased mental health symptomology, indicating the very real and ongoing pressure for the women to conceive above all, even at the expense of giving up social support by keeping details of their struggles private.

Thus, the cultural concepts and traditional understandings of infertility inherent in the socially debilitating stigma of infertility require a shift in thinking ${ }^{23}$ for women which is unlikely to occur by itself for many. Indeed, we feel that this calls for interventions that help the women to manage their stress throughout the experience of infertility - with or without treatment, and regardless of outcome. An intervention that stresses their worth regardless of motherhood and equips them with stress selfmanagement skills. Women continue to experience more self and social blame for infertility regardless of etiology. ${ }^{15}$ Therefore, psychosocial support is paramount, and strong advocacy for such is needed. ${ }^{46}$ Therapeutic counseling has been shown to improve depression and anxiety related to infertility. ${ }^{13,17}$ Likewise, infertility educational counseling provided by non-mental health specialists and mind-body modalities such as relaxation, meditation, prayer, and yoga have been shown to effectively decrease women's perception of infertility stigma and distress. ${ }^{13,16,26}$

While such programs are clearly needed to assist the women to deal with their emotional troubles related to infertility, it is not clear how open women would be to participate in such programs, given both the high rates of stigma associated with mental health and related health seeking, which is further aggravated by the stigma of infertility. We conducted this research in preparation for such an intervention; therefore, we explored who among our respondents would be interested in participating in such a program and found that 24 of our 74 participants (32\%) indicated interest. In subgroup analyses not presented here due to power issues, we found that the women who identified themselves as interested in an intervention had significantly poorer mental health and that they were also more affected by stigma. Indeed, when we explored nuances of this subgroup we found that years married, public stigma and infertility stigma total score explained significant variance in HSCL (35\% + ), confirming the importance of stigma and years of struggle with infertility with respect of serious mental health consequences. Future interventions should target both women who are early in their fertility struggles from a preventive perspective, as well as women who have been married and infertile longer, to support them in their deepening crises. Regardless, a non-labeling health promotion approach should be used to help protect women from the results of the double stigma of mental health and infertility.

While we were able to gain substantive insights in the continuing challenges low-income women have with respect to infertility, there are some limitations to note. These include our relatively small sample, with data collected cross-sectionally and relying on self-report. While infertility prevalence in India would support larger samples, the associated stigma, research naivete, and vulnerable social status of these women likely discouraged broader participation. Therefore, the results from this sample may not be generalizable to the entire population of infertile women in India. Additionally, only women were included in this study; therefore, the perceptions of their husbands and other family or community members are not represented. Further studies exploring additional areas of concern and including men would expand understanding of infertility and mental health sequelae in this sector of Indian society.

Nonetheless, this study adds importantly to the limited literature on infertility as experienced by low-income Indian women. Strengths include that this was a community sample, rather than from a specialized infertility clinic. As expected, we found elevated distress- 
related infertility stigma in all of our respondents, resulting in elevated HSCL (depression and anxiety symptomology), which needs to inform future interventions. Importantly, a third of the women in this sample indicated a desire for future intervention and this sub-group were more likely to have self-identified psychosocial problems (ie, self-identified need) and indeed had the highest HSCL scores. Additionally, this subgroup was more likely to endorse social norms pertaining to infertility (which negatively affect their well-being), and experienced more family stigma due to their infertility. However, they also had greater autonomy, indicating they would be able to participate in an intervention which is not necessarily a given in India due to women's generally low autonomy. Thus, our data points to the importance of and feasibility for resiliency promoting community-based interventions, given the impact of fertility challenges in this pronatalist society. As part of good public health practice programs to promote factual awareness of infertility should also be implemented addressing family and community attitudes, to reduce infertility stigma.

Since we are unable to assign causality to our findings, the observed mental health symptomology may be a preexisting condition which makes infertility experiences more challenging, or may occur as a result of infertility. 5,12,26 Regardless, infertility distress, anxiety, and depression actually worsen infertility and reduces the likelihood of conceiving with treatment. ${ }^{13,14,26}$ For the few in LMICs who can afford allopathic treatment or have taken out loans to make it possible, ${ }^{6}$ the current COVID19 pandemic is a concern as services are further affected and women have limited time to address issues that may impact their fertility. Some, who already argue against infertility services in a world where overpopulation is a major concern, ${ }^{6}$ further argue that during the pandemic, precious healthcare resources should be reassigned or only essential services offered. ${ }^{50-52}$ However, from the perspective of infertile couples, the disruption in treatment due to a change in healthcare guidelines or due to quarantine conditions, ${ }^{52}$ means a significant loss in time and effort and treatment already paid for because they may have to begin again after the pandemic resolves. ${ }^{6,53}$ Such a situation greatly compounds stress and mental health risk related to infertility. ${ }^{54}$ Therefore, regardless of the timing of mental health symptomology, or additional circumstances, mental health represents a critical point for treatment and prevention. Thus, innovative mental health programs and policy changes are needed to address the needs of low-income women residing in Mumbai slums and similar settings, as they face the challenges associated with infertility.

\section{Conclusions}

While all of our low-income Indian women with infertility challenges had poor mental health as a result, within this sample, the subgroup of women who expressed an interest in a future intervention, were the very women most in need according to statistical analyses. In a social context where infertility is highly stigmatized, it is noteworthy that these women have the self-insight to seek help when offered the possibility of community-based women's resiliency program.

\section{Funding}

Research Affairs, Loma Linda University Health.

\section{Disclosure}

The authors report no conflicts of interest for this work.

\section{References}

1. World Health Organization. Multiple Definitions of Infertility. WHO; 2020:2020.

2. Mascarenhas MN, Flaxman SR, Boerma T, Vanderpoel S, Stevens GA. National, regional, and global trends in infertility prevalence since 1990: a systematic analysis of 277 health surveys. PLoS Med. 2012;9(12):e1001356. doi:10.1371/journal.pmed.1001356

3. Sarkar S, Gupta P. Socio-demographic correlates of women's infertility and treatment seeking behavior in India. J Reprod Infertil. 2016;17(2):123.

4. Lowdermilk DL, Perry SE, Cashion MC, Alden KR, Olshansky E. Maternity and Women's Health Care. Elsevier Health Sciences; 2019.

5. De D, Roy PK, Sarkhel S. A psychological study of male, female related and unexplained infertility in Indian urban couples. $J$ Reprod Infant Psychol. 2017;35(4):353-364.

6. Silberner J. Infertility as a neglected disease. Global health now. 2020 (GHN exclusive, family planning, human rights, maternal health, neglected diseases, reproductive health, research). Available from: https://www.globalhealthnow.org/2020-06/infertility-neglected-

disease?utm_source $=$ Global + Health $+\mathrm{NOW}+$ Main + List\&utm_cam paign $=\mathrm{c} 7 \mathrm{ad} 91 \mathrm{c} 370$ -

EMAIL_CAMPAIGN_2020_06_10_02_02\&utm_medium=emai $1 \&$ utm_term $=0 \_8 \mathrm{~d} 0 \mathrm{~d} 06 \overline{2} \mathrm{dbd}-\overline{\mathrm{c}} \overline{\mathrm{ad}} \mathrm{a} 91 \mathrm{c} 3 \overline{3} 70-\overline{3} 032593$. Accessed June $10,20 \overline{20}$.

7. Schuiling KD, Likis FE. Women's Gynecologic Health. Jones \& Bartlett Learning; 2016.

8. Nicola Z, Federica B, Simone P, Elettra V, Saverio CF. Infertility worldwide: the lack of global pediatric andrologists and prevention. In: Male Reproductive Health. IntechOpen; 2019.

9. Inhorn MC. Global infertility and the globalization of new reproductive technologies: illustrations from Egypt. Soc Sci Med. 2003;56 (9):1837. doi:10.1016/S0277-9536(02)00208-3

10. Venkatesan L. Infertility. In: Churness V, Roberts LR, editors. Midwifery for Nurses in India. Chennai, India: Ecumenical Book Services; 2018:370-385. 
11. Marshall J, Raynor M, eds. Myles Textbook for Midwives. 16th ed. Edinburgh, UK: Elsevier; 2014.

12. Satheesan SC, Satyaranayana VA. Quality of marital relationship, partner violence, psychological distress, and resilience in women with primary infertility. Int $J$ Community Med Public Health. 2018;5(2):734-739.

13. Bhat A, Byatt N. Infertility and perinatal loss: when the bough breaks. Curr Psychiatry Rep. 2016;18(3):1-11. doi:10.1007/s11920016-0663-8

14. Saleem S, Qureshi NS, Mahmood Z. Attachment, perceived social support and mental health problems in women with primary infertility. Int J Reprod Contracept Obstet Gynecol. 2019;8(6):2534. doi:10.18203/2320-1770.ijrcog20192463

15. Patel A, Sharma P, Kumar P, Binu V. Sociocultural determinants of infertility stress in patients undergoing fertility treatments. J Hum Reprod Sci. 2018;11(2):172. doi:10.4103/jhrs.JHRS_134_17

16. Moudi Z, Piramie R, Ghasemi M, Ansari H. Effect of an infertility counseling program on perceived stigma among infertile female candidates for intra-uterine insemination. $J$ Midwifery Reprod Health. 2019;7(4):1870-1879.

17. Kharde SN, Pattad S, Bhogale GS. Effectiveness of a therapeutic counseling intervention for depression, anxiety, self esteem and marital adjustment among infertile women. Int J Nurs Educ. 2012;4 (2):151-154.

18. Roberts LR, Anderson BA, Lee JW, Montgomery SB. Grief and women: stillbirth in the social context of India. Int $J$ Childbirth. 2012;2(3):187-198. doi:10.1891/0886-6708.2.3.187

19. Roberts LR, Montgomery SB. India's distorted sex ratio: dire consequences for girls. J Christ Nurs. 2016;33(1):E7-E15. doi:10.1097/ CNJ.0000000000000244

20. Roberts L, Montgomery S, Ganesh G, Kaur HP, Singh R. Addressing stillbirth in India must include men. Issues Ment Health Nurs. 2017;38(7):590-599. doi:10.1080/01612840.2017.1294220

21. Roberts LR. The lived experience of childbearing: the lifelong impact. In: Anderson BA, Roberts LR, editors. The Maternal Health Crisis in America: Nursing Implications for Advocacy and Practice. New York, NY: Springer; 2019:198.

22. Varney H, Burst HV, Kriebs JM, Gegor CL. Varney's Midwifery. Jones \& Bartlett Learning; 2004.

23. Bharadwaj A. Conceptions: Infertility and Procreative Technologies in India. Vol. 34. Berghahn Books; 2016.

24. Nouman H, Benyamini Y. The contribution of social-environmental factors to the emotional adjustment of Israeli religious Jewish women coping with infertility. Women Health. 2019;59(4):433-448. doi:10.1080/03630242.2018.1492498

25. McCutcheon JM. Reviewing pronatalism: a summary and critical analysis of prior research examining attitudes towards women without children. J Child Fam Stud. 2018;1-22.

26. Patel A, Sharma P, Narayan P, Binu V, Dinesh N, Pai PJ. Prevalence and predictors of infertility-specific stress in women diagnosed with primary infertility: a clinic-based study. J Hum Reprod Sci. 2016;9 (1):28. doi:10.4103/0974-1208.178630

27. Corbin J, Strauss A. Basics of Qualitative Research: Techniques and Procedures for Developing Grounded Theory. Thousand Oaks, CA: Sage; 2008.

28. Park K. Park's Textbook of Preventive and Social Medicine. 20th ed. Jabalpur, India: Banarsidas Bhanot; 2009.

29. Jones P, Lee J, Phillips L, Zhang X, Jaceldo K. An adaptation of Brislin's translation model for cross-cultural research. Nurs Res. 2001;50(5):300-304. doi:10.1097/00006199-2001090 00-00008

30. Syed HR, Zachrisson HD, Dalgard OS, Dalen I, Ahlberg N. Concordance between hopkins symptom checklist (HSCL-10) and Pakistan anxiety and depression questionnaire (PADQ), in a rural self-motivated population in Pakistan. BMC Psychiatry. 2008;8 (1):1-12. doi:10.1186/1471-244X-8-59
31. Roberts LR, Montgomery SB. Mindfulness-based intervention for perinatal grief after stillbirth in rural India. Issues Ment Health Nurs. 2015;36(3):222-230. doi:10.3109/01612840.2014.962676

32. Mosley-Williams A, Lumley MA, Gillis M, Leisen J, Guice D. Barriers to treatment adherence among African American and white women with systemic lupus erythematosus. Arthritis Rheum. 2002;47 (6):630-638. doi:10.1002/art.10790

33. Roberts L, Montgomery S. Mindfulness-based intervention for perinatal grief education and reduction among poor women in Chhattisgarh, India: a pilot study. Interdiscip J Best Pract Glob Dev. 2016;2(1).

34. Roberts LR, Montgomery S, Lee JW, Anderson BA. Social and cultural factors associated with perinatal grief in Chhattisgarh, India. J Community Health. 2012;37(3):572-582. doi:10.1007/s 1090 0-011-9485-0

35. Feder A, Ahmad S, Lee EJ, et al. Coping and PTSD symptoms in Pakistani earthquake survivors: purpose in life, religious coping and social support. J Affect Disord. 2013;147(1-3):156-163. doi:10.1016/ j.jad.2012.10.027

36. John E, Fetzer Institute. Multidimensional Measurement of Religiousness/Spirituality for Use in Health Research. Kalamazoo, MI: John E. Fetzer Institute; 1999:96.

37. Hatton C, Emerson E. The development of a shortened 'ways of coping' questionnaire for use with direct care staff in learning disability services. Mental Handicap Res. 1995;8(4):237-251. doi:10.11 11/j.1468-3148.1995.tb00160.x

38. Mascha K. Staff morale in day care centres for adults with intellectual disabilities. J Appl Res Intellect Disabil. 2007;20(3):191-199. doi:10.1111/j.1468-3148.2006.00316.x

39. Fu B, Qin N, Cheng L, et al. Development and validation of an infertility stigma scale for Chinese women. $J$ Psychosom Res. 2015;79(1):69-75. doi:10.1016/j.jpsychores.2014.11.014

40. Rajabi G, Amiri Asl J, Jelodari A. Assessing reliability and validity of the persian version of infertility stigma scale (ISS) in infertile women. Sci J Hamadan Nurs Midwifery Fac. 2017;25(4):104-113.

41. Çapık A, Aksoy M, Yılmaz E, Yılmaz F. Infertility stigma scale: a psychometric study in a Turkish sample. Perspect Psychiatr Care. 2019;55(2):328-335. doi:10.1111/ppc. 12360

42. Diener E, Emmons RA, Larsen RJ, Griffin S. The satisfaction with life scale. J Pers Assess. 1985;49(1):71. doi:10.1207/s15327752 jpa4901_13

43. Diener E, Inglehart R, Tay L. Theory and validity of life satisfaction scales. Soc Indic Res. 2013;112(3):497-527. doi:10.1007/s11205012-0076-y

44. Ozan YD, Okumuş H. Effects of nursing care based on watson's theory of human caring on anxiety, distress, and coping, when infertility treatment fails: a randomized controlled trial. Int J Caring Sci. 2017;6(2):95. doi:10.15171/jcs.2017.010

45. Driscoll MA, Davis MC, Aiken LS, et al. Psychosocial vulnerability, resilience resources, and coping with infertility: a longitudinal model of adjustment to primary ovarian insufficiency. Ann Behav Med. 2016;50(2):272-284.

46. Gerrits T, Van Rooij F, Esho T, et al. Infertility in the global south: raising awareness and generating insights for policy and practice. Facts Views Vis Obgyn. 2017;9(1):39.

47. Andavarapu D, Edelman DJ, Monangi N. Victims or survivors: resilience from the slum dwellers' perspective. In: Galderisi A, Colucci A, editors. Smart, Resilient and Transition Cities: Emerging Approaches and Tools for a Climate-Sensitive Urban Development. Amsterdam, Netherlands: Elsevier; 2018:320.

48. Ramanath R. Defying NGO-ization? Lessons in livelihood resilience observed among involuntarily displaced women in Mumbai, India. World Dev. 2016;84:1-17. doi:10.1016/j.worlddev.2016.04.007

49. Kalokhe AS, Iyer SR, Kolhe AR, et al. Correlates of domestic violence experience among recently-married women residing in slums in Pune, India. PLoS One. 2018;13(4). 
50. Lambalk C, van Wely M, Kirkegaard K, Williams A, de Geyter C. Safety first-assisted human reproduction second. Hum Reprod. 2020;35(4):741-742. doi:10.1093/humrep/deaa075

51. Ehrlich H, McKenney M, Elkbuli A. Strategic planning and recommendations for healthcare workers during the COVID-19 pandemic. Am J Emerg Med. 2020.

52. Rodriguez-Wallberg KA, Wikander I. A global recommendation for restrictive provision of fertility treatments during the COVID-19 pandemic. Acta Obstet Gynecol Scand. 2020;99(5):569. doi:10.11 11/aogs. 13851

53. de Souza M, Nakagawa H, Taitson PF, Cordts EB, Antunes RA. Management of ART and COVID-19: Infertility in Times of PanDemic. What Now? 2020.

54. Turocy JM, Robles A, Hercz D, D'Alton M, Forman EJ, Williams Z. The emotional impact of the ASRM guidelines on fertility patients during the covid-19 pandemic. medRxiv. 2020.

\section{Publish your work in this journal}

The International Journal of Women's Health is an international, peerreviewed open-access journal publishing original research, reports, editorials, reviews and commentaries on all aspects of women's healthcare including gynecology, obstetrics, and breast cancer. The manuscript management system is completely online and includes a very quick and fair peer-review system, which is all easy to use. Visit http://www.dovepress.com/testimonials.php to read real quotes from published authors. 